\title{
Pathogenic Diversity of Ascochyta rabiei Isolates and Identification of Resistance Sources in Core Collection of Chickpea Germplasm
}

\author{
Somayeh Farahani ${ }^{1}$, Reza Talebi ${ }^{20}{ }^{2 *}$, Mojdeh Maleki ${ }^{1 *}$, Rahim Mehrabi ${ }^{3}$, and Homayoun Kanouni ${ }^{4}$ \\ ${ }^{I}$ Department of Plant Protection, Varamin-Pishva Branch, Islamic Azad University, Varamin 3381774895, Iran \\ ${ }^{2}$ Department of Agronomy \& Plant Breeding, College of Agriculture, Sanandaj Branch, Islamic Azad University, \\ Sanandaj 618, Iran \\ ${ }^{3}$ Department of Biotechnology, College of Agriculture, Isfahan University of Technology, Isfahan 8415683111, Iran \\ ${ }^{4}$ Kordestan Agricultural and Natural Resources Research and Education Center, Agricultural Research, Education and \\ Extension Organization (AREEO), Sanandaj 33623351, Iran
}

(Received on December 23, 2018; Revised on April 26, 2019; Accepted on May 17, 2019)

Ascochyta blight caused by Ascochyta rabiei (Pass.) Lab. (Telomorph: Didymella rabiei) (Kov.) is one of the most important fungal diseases in chickpea worldwide. Knowledge about pathogen aggressiveness and identification resistance sources to different pathotypes is very useful for proper decisions in breeding programs. In this study, virulence of $32 \mathrm{~A}$. rabiei isolates from different part of Iran were analyzed on seven chickpea differentials and grouped into six races based on 0-9 rating scale and susceptibility/resistant pattern of chickpea differentials. The least and most frequent races were race $V$ and race $I$, respectively. Race $V$ and $V I$ showed highly virulence on most of differential, while race I showed least aggressiveness. Resistance pattern of 165 chickpea genotypes also were tested against six different $A$. rabiei races. ANOVA analysis showed high significant difference for isolate, chickpea genotypes and their interactions. Overall chickpea $\times$ isolate (race)

\footnotetext{
*Co-corresponding authors.

Reza Talebi

Phone) +98-8733367112, FAX) +98-8733367110

E-mail)srtalebi@yahoo.com

ORCID

https://orcid.org/0000-0001-9109-7677

Mojdeh Maleki

Phone) +98-2136220650, FAX) +98-2136724767

E-mail)mojdehmaleki@yahoo.com

(c) This is an Open Access article distributed under the terms of the Creative Commons Attribution Non-Commercial License (http:// creativecommons.org/licenses/by-nc/4.0) which permits unrestricted noncommercial use, distribution, and reproduction in any medium, provided the original work is properly cited.
}

Articles can be freely viewed online at www.ppjonline.org. interactions, 259 resistance responses (disease severity $\leq 4)$ were identified. Resistance spectra of chickpea genotypes showed more resistance rate to race I $(49.70 \%)$ and race III $(35.15 \%)$, while there were no resistance genotypes to race VI. Cluster analysis based on disease severity rate, grouped chickpea genotypes into four distinct clusters. Interactions between isolates or races used in this study, showed the lack of a genotype with complete resistance. Our finding for virulence pattern of $A$. rabiei and newly identified resistance sources could be considerably important for integration of ascochyta blight resistance genes into chickpea breeding programs and proper decision in future for germplasm conservation and diseases management.

Keywords : Ascochyta blight, chickpea, pathogenic variability, resistance sources

Handling Editor : Park, Chang-Jin

Chickpea (Cicer arietinum L.) is one of the most important cool season legume crop and play important roles in human diet as a cheap protein source. Legume crops as well as chickpea can fix nitrogen through symbiotic bacteria in their root nodules and play important roles in crop rotation and sustainable agriculture (Gan et al., 2006; Hajibarat et al., 2015). Chickpea is originated from Near Eastern (India and Afghanistan), Central Asian (Turkey, Iran) and Mediterranean regions (Israel, Syria and North Africa) (Talebi et al., 2008; van der Maesen, 1987). Chickpea production globally is low and narrow genetic base of cultivated chickpea making them very susceptible and vulnerable to abiotic 
and biotic stresses such as Ascochyta blight (AB) and Fusarium wilt (Ghaffari et al., 2014; Jamalabadi et al., 2013). Ascochyta blight disease caused by Ascochyta rabiei (Pass.) Lab. (Telomorph: Didymella rabiei) (Kov.) is one of the most destructive diseases in chickpea worldwide that annually showed epidemic in cool and humid area (Ahmad et al., 2014; Pande et al., 2005). Chickpea yield losses caused by $A$. rabiei in favorable cool and humid climates in in Iran may reach up to $100 \%$ (Shokouhifar et al., 2003; Vail and Banniza, 2008; Younessi et al., 2004). A. rabiei have sexual and asexual fruiting bodies, therefore high degree of genetic diversity and pathogenicity has been reported in most epidemic regions for $A$. rabiei (Atik et al., 2011; Rhaiem et al., 2008; Sharma and Ghosh, 2016). Highly virulence diversity of $A$. rabiei with six physiological races in Syria and Lebanon (Reddy and Kabbabeh, 1985), 11 pathotypes in USA (Jan and Weise, 1991) and 14 pathotypes group in Canada (Chongo et al., 2004) has been reported. Different strategies for integrated diseases management in chickpea including crop rotation, adjusting sowing dates, application of fungicides and use of AB-resistance sources have been recommended in chickpea production (Ben Mohamed et al., 2010; Kimurto et al., 2013; Vafaei et al., 2015). Changes in pathogen population, mutation and variability of pathotypes in A. rabiei lead to breakdown durable resistant in common resistance sources in chickpea breeding programs (Kanouni et al., 2011).

Therefore, the knowledge about pathogen aggressiveness and pathotypes differentiation could likely lead to better management of disease and proper decisions in breeding programs (Aghamiri et al., 2015; Ahmad et al., 2014; Ali et al., 2012; Baite and Dubey, 2018). In other hands, identification of new sources of resistant to A. rabiei can help and support breeders to improve commercial cultivars for resistance to this disease. Therefore, screening diverse germplasm sources is necessary to identify and integrate resistant genotypes in breeding programs (Ahmad et al., 2014; Kimurto et al., 2013). Sufficient genetic variation for resistance to A. rabiei in chickpea has been reported previously (Bhardwaj et al., 2010; Labdi et al., 2013). Genetic of resistance to A. rabiei is controlled by a single recessive gene (Singh and Reddy, 1990) or a dominant gene (Singh and Reddy, 1983). Previous studies demonstrated that the resistance to $\mathrm{AB}$ may be controlled by complex genetic inheritance of two dominant genes or complementary genes (Dey and Singh, 1993; Malik et al., 2005).

Despite this information, the identification of new resistance sources remains a challenging proposition due to complex genetic base of resistance, high genetic diversity of pathogen population and emergence of new pathotypes of A. rabiei (Sharma and Ghosh, 2016). Breeding programs for resistance to A. rabiei and fusarium wilt are the major focuses in chickpea breeding programs in Iran. Landraces and local Iranian genotypes are very susceptible to $A$. $r a-$ biei (Kanouni et al., 2011), therefore, most widely used resistance sources in chickpea breeding programs have been supplied by International Crops Research Institute for the Semi-Arid Tropics (ICRISAT) and International Center for Agriculture Research in the Dry Areas (ICARDA).

The present study was aimed to determine the pathogenic variability identification of $32 \mathrm{~A}$. rabiei isolates collected from west of Iran and identification of resistance spectra of 165 chickpea genotypes against six different known $A$. rabiei races. Most of chickpea genotypes used in this study imported from ICARDA and used as advanced breeding lines in chickpea programs.

\section{Materials and Methods}

A. rabiei sampling and isolation. Ascochyta blight infected chickpea fields were chosen in Kermanshah and Illam province (west of Iran). Thirty-two separate fields (10 km distance) were chosen and infected leaves stem and pods were collected during 2017 and 2018 growing season. To isolate the $A$. rabiei fungus, infected samples were surfacesterilized with hypochlorite sodium $(0.5 \%)$ for $2 \mathrm{~min}$, and washed twice with sterilized distilled water. Samples were plated on CSMDA (chickpea seed meal $40 \mathrm{~g}$, dextrose 20 $\mathrm{g}$ and agar $18 \mathrm{~g}$ in 11 sterilized distilled water). Plates were incubated for $7-10$ days at $20-22^{\circ} \mathrm{C}$. Single pycnidia isolates were purified from plates and stored on CSMDA for pathogenicity tests.

Pathogenicity test. The pathogenicity test was conducted on susceptible cultivar "Bivanij" under controlled greenhouse. Pre-cultures of $32 \mathrm{~A}$. rabiei isolates were prepared on CSMDA medium. 2-4 mm of these pre-cultures was then used to inoculate $100 \mathrm{ml}$ Erlenmeyer flask containing $40 \mathrm{ml}$ of potato dextrose broth (PDB) and incubated on shaker for five days at $20-22^{\circ} \mathrm{C}$. Ten days oil plants of susceptible check cultivar "Bivanij" were inoculated using $A$. rabiei medium adjusted to $5 \times 10^{5}$ spores $/ \mathrm{ml}$ supplemented with $0.15 \%$ of Tween 20 (MERCK $^{\circledR}$, Nottingham, UK). The inoculated plants were covered by dark plastic which was removed after $24 \mathrm{~h}$. The inoculated plants were kept in greenhouse for 14 days. During the experiment, environmental conditions were kept at $22 / 18^{\circ} \mathrm{C}$ (day/night rhythm) with 14-h photoperiod and $90 \%$ humidity. 14-days after inoculation, disease reaction of susceptible check against A. rabiei isolates was assessed using 0-9 rating scale as de- 
scribed previously (Chongo et al., 2004; Nene et al., 1981; Pande et al., 2011) as follow: $0=$ no symptom or small lesions (highly resistant); $1=$ few and small lesions on the apical stems (highly resistant); 2 = small girdling stem lesions low down on some branches (resistant); $3=$ lesions up to 5-6 $\mathrm{mm}$ in size and 1-2 branches broken (resistant); $4=$ lesions (2-5 $\mathrm{mm}$ in size) obviously on most part of plant and several branches broken (moderately resistant); $5=$ many large lesions and defoliation initiated and half of branches broken (moderately susceptible); $6=$ lesions as in 5 , with more defoliation, broken stems and dry branches (susceptible); 7 = many large lesions as in 5 and 6, with obviously defoliation and broken branches (up to $70 \%$ ) and up to $25 \%$ of plants killed (susceptible); $8=$ symptoms as in 7 and up to $50 \%$ of plants killed (highly susceptible); $9=$ symptoms as in 8 and all plants killed (highly susceptible).

Differential genotypes and virulence diversity of $A$. rabiei isolates. Seven chickpea genotypes (Table 1) were obtained from ICRISAT and ICARD as identified previously (Chen et al., 2004; Kanouni et al., 2011; Shahriari et al., 2016) were utilized as differentials representing resistant (ILC202 and ILC72), moderately resistance (ILC5928 and ICC3996), moderately susceptible (ILC194) and susceptible (ILC1929 and PCH215) genotypes. The pathogenicity test of $32 \mathrm{~A}$. rabiei isolates were assessed on seven chickpea differentials based on their virulence/avirulence responses with different $A$. rabiei isolates. Five seeds form each genotype was sown in pods containing soil, peat and sand $(1: 1: 2, \mathrm{v} / \mathrm{v} / \mathrm{v})$. Pathogenicity test procedures (inoculation and disease reaction) were same as described for pathogenicity test. 14-days after inoculation differentials were assessed for their reaction against $32 \mathrm{~A}$. rabiei isolates based on 0-9 rating scale as described previously (Chongo et al., 2004; Nene et al., 1981; Pande et al., 2011). Physiologic races of 32 isolates of $A$. rabiei collected were determined using seven chickpea standard differential cultivars as described by Shahriari et al. (2016). Experiment was carried out in randomized complete factorial design with three replications.

Table 1. Analysis of variance of the interaction between chickpea differential cultivars and Ascochyta rabiei isolates under greenhouse conditions

\begin{tabular}{lccc}
\hline S.O.V & $d f$ & Mean of Square & $F$ value \\
\hline Isolate & 31 & 13.21 & $7.42^{* *}$ \\
Differentials & 6 & 10.36 & $5.82^{* *}$ \\
Isolate $\times$ differentials & 186 & 7.57 & $4.25^{* *}$ \\
Error & 448 & 1.78 & \\
\hline
\end{tabular}

Characterization of resistance sources in chickpea germplasm. One hundred and sixty five chickpea genotypes (20 Iranian landrace Desi accessions and 145 Kabuli accessions) were assessed for resistance/susceptibility pattern against different $A$. rabiei races. Genotypes name, origin and pedigree of chickpea genotypes summarized in Supplementary Table 1.

Six isolates that representing different races of $A$. rabiei were chosen from first experiment (AR9, AR13, AR18, AR23, AR28 and AR32). To evaluate 165 chickpea genotypes against $A$. rabiei races, five seeds form each genotype was sown in pods containing soil, peat and sand (1:1:2, v/ $\mathrm{v} / \mathrm{v}$ ) in randomized complete factorial design with three replications under greenhouse condition. Fourteen days old seedlings were spray-inoculated with $5 \times 10^{5}$ spores $/ \mathrm{ml}$ suspension. During the experiment, environmental conditions were kept at $22 / 18^{\circ} \mathrm{C}$ (day/night rhythm) with $14-\mathrm{h}$ photoperiod and $90 \%$ humidity. Two weeks after inoculation, disease ratings of Ascochyta blight were made by using 0-9 rating scale (Chongo et al., 2004; Nene et al., 1981; Pande et al., 2011).

Data analysis. The experimental design of the present study was a randomized complete factorial design with three replications. Analysis of variance (ANOVA) of the data for differential and chickpea germplasm was performed using SAS program (SAS Institute Inc, 2001). Principal component analysis (PCA) and cluster analysis of differential and chickpea genotypes according to disease severity rate data by each isolate as well as for tested isolates were performed using the un-weighted pair-group method (UPGMA) and the dissimilarity matrix was measured using ward's method implemented in SAS JMP software (SAS 2012).

\section{Results}

A. rabiei isolates virulence and race identification. ANOVA analysis showed high significant effects $(P \leq 0.01)$ of isolates, differentials and isolate $\times$ differentials interactions based on Ascochyta blight scores on 0-9 scale (Table 1). The resistant and susceptible pattern of seven differential genotypes and susceptible cultivar "Bivanij" are given in Table 2. Results from susceptible cultivar showed high aggressiveness (grades from 7 to 9) for all tested $A$. rabiei races. For all isolates, symptoms initially appeared as irregular white spots on leaves and light green lesions on stems between 4 to 7 days after inoculation. Diseases severity increased with time and after 14 days dried broken stems and killed plants were observed in susceptible check 
Table 2. Disease reaction and pathogenicity test of 32 Ascochyta rabiei isolates of chickpea differentials

\begin{tabular}{|c|c|c|c|c|c|c|c|c|c|c|}
\hline Isolate & $\begin{array}{l}\text { Collection } \\
\text { site }\end{array}$ & $\begin{array}{c}\text { Bibvanij } \\
\text { (Susceptible } \\
\text { check) }\end{array}$ & ILC1929 & ILC5928 & ILC202 & ILC72 & ICC3996 & ILC194 & $\mathrm{PCH} 215$ & $\begin{array}{c}\text { Pathogenic } \\
\text { group } \\
\text { (Race) }\end{array}$ \\
\hline AR1 & Kermanshah & $7(\mathrm{~S})$ & S & $\mathrm{R}$ & $\mathrm{R}$ & $\mathrm{R}$ & $\mathrm{R}$ & $\mathrm{R}$ & $\mathrm{R}$ & I \\
\hline AR2 & Kermanshah & $7(\mathrm{~S})$ & S & $\mathrm{R}$ & $\mathrm{R}$ & $\mathrm{R}$ & $\mathrm{R}$ & $\mathrm{R}$ & $\mathrm{R}$ & I \\
\hline AR3 & Kermanshah & $8(\mathrm{~S})$ & $\mathrm{S}$ & $\mathrm{R}$ & $\mathrm{R}$ & $\mathrm{R}$ & $\mathrm{R}$ & $\mathrm{R}$ & $\mathrm{R}$ & I \\
\hline AR4 & Kermanshah & $8(\mathrm{~S})$ & $\mathrm{S}$ & $\mathrm{R}$ & $\mathrm{R}$ & $\mathrm{R}$ & $\mathrm{R}$ & $\mathrm{R}$ & $\mathrm{R}$ & I \\
\hline AR5 & Kermanshah & $7(\mathrm{~S})$ & S & $\mathrm{R}$ & $\mathrm{R}$ & $\mathrm{R}$ & $\mathrm{R}$ & $\mathrm{R}$ & $\mathrm{R}$ & I \\
\hline AR6 & Kermanshah & $8(\mathrm{~S})$ & S & $\mathrm{R}$ & $\mathrm{R}$ & $\mathrm{R}$ & $\mathrm{R}$ & $\mathrm{R}$ & $\mathrm{R}$ & I \\
\hline AR7 & Kermanshah & $7(\mathrm{~S})$ & $\mathrm{S}$ & $\mathrm{R}$ & $\mathrm{R}$ & $\mathrm{R}$ & $\mathrm{R}$ & $\mathrm{R}$ & $\mathrm{R}$ & I \\
\hline AR8 & Illam & $7(\mathrm{~S})$ & S & $\mathrm{R}$ & $\mathrm{R}$ & $\mathrm{R}$ & $\mathrm{R}$ & $\mathrm{R}$ & $\mathrm{R}$ & I \\
\hline AR9 & Illam & $8(\mathrm{~S})$ & $\mathrm{S}$ & $\mathrm{R}$ & $\mathrm{R}$ & $\mathrm{R}$ & $\mathrm{R}$ & $\mathrm{R}$ & $\mathrm{R}$ & I \\
\hline AR10 & Kermanshah & $8(\mathrm{~S})$ & S & $\mathrm{R}$ & $\mathrm{R}$ & $\mathrm{R}$ & $\mathrm{R}$ & $\mathrm{R}$ & S & II \\
\hline AR11 & Kermanshah & $7(\mathrm{~S})$ & S & $\mathrm{R}$ & $\mathrm{R}$ & $\mathrm{R}$ & $\mathrm{R}$ & $\mathrm{R}$ & S & II \\
\hline AR12 & Kermanshah & $8(\mathrm{~S})$ & $\mathrm{S}$ & $\mathrm{R}$ & $\mathrm{R}$ & $\mathrm{R}$ & $\mathrm{R}$ & $\mathrm{R}$ & S & II \\
\hline AR13 & Kermanshah & $8(\mathrm{~S})$ & S & $\mathrm{R}$ & $\mathrm{R}$ & $\mathrm{R}$ & $\mathrm{R}$ & $\mathrm{R}$ & S & II \\
\hline AR14 & Kermanshah & $8(\mathrm{~S})$ & S & $\mathrm{R}$ & $\mathrm{R}$ & $\mathrm{R}$ & $\mathrm{R}$ & $\mathrm{R}$ & S & II \\
\hline AR15 & Kermanshah & $7(\mathrm{~S})$ & S & S & $\mathrm{R}$ & $\mathrm{R}$ & $\mathrm{R}$ & S & S & III \\
\hline AR16 & Kermanshah & $8(\mathrm{~S})$ & S & $\mathrm{S}$ & $\mathrm{R}$ & $\mathrm{R}$ & $\mathrm{R}$ & S & S & III \\
\hline AR17 & Kermanshah & $7(S)$ & $\mathrm{S}$ & $\mathrm{S}$ & $\mathrm{R}$ & $\mathrm{R}$ & $\mathrm{R}$ & S & S & III \\
\hline AR18 & Kermanshah & $8(\mathrm{~S})$ & S & $\mathrm{S}$ & $\mathrm{R}$ & $\mathrm{R}$ & $\mathrm{R}$ & S & S & III \\
\hline AR19 & Kermanshah & $8(\mathrm{~S})$ & S & S & $\mathrm{R}$ & $\mathrm{R}$ & $\mathrm{R}$ & S & S & III \\
\hline AR20 & Kermanshah & $7(\mathrm{~S})$ & $\mathrm{S}$ & $\mathrm{S}$ & $\mathrm{R}$ & $\mathrm{R}$ & $\mathrm{R}$ & S & S & III \\
\hline AR21 & Kermanshah & $8(\mathrm{~S})$ & S & S & $\mathrm{R}$ & $\mathrm{R}$ & $\mathrm{R}$ & S & S & III \\
\hline AR22 & Illam & $7(\mathrm{~S})$ & S & S & $\mathrm{R}$ & $\mathrm{R}$ & $\mathrm{R}$ & S & S & III \\
\hline AR23 & Kermanshah & $8(\mathrm{~S})$ & S & $\mathrm{R}$ & $\mathrm{R}$ & $\mathrm{R}$ & S & S & S & IV \\
\hline AR24 & Kermanshah & $7(\mathrm{~S})$ & $\mathrm{S}$ & $\mathrm{R}$ & $\mathrm{R}$ & $\mathrm{R}$ & S & S & S & IV \\
\hline AR25 & Kermanshah & $7(\mathrm{~S})$ & $\mathrm{S}$ & $\mathrm{R}$ & $\mathrm{R}$ & $\mathrm{R}$ & S & S & S & IV \\
\hline AR26 & Illam & $7(\mathrm{~S})$ & S & $\mathrm{R}$ & $\mathrm{R}$ & $\mathrm{R}$ & S & S & S & IV \\
\hline AR27 & Illam & $8(\mathrm{~S})$ & $\mathrm{S}$ & $\mathrm{R}$ & $\mathrm{R}$ & $\mathrm{R}$ & S & S & S & IV \\
\hline AR28 & Kermanshah & $8(\mathrm{~S})$ & S & $\mathrm{R}$ & $\mathrm{R}$ & S & S & S & S & $\mathbf{V}$ \\
\hline AR29 & Kermanshah & $8(\mathrm{~S})$ & $\mathrm{S}$ & $\mathrm{R}$ & $\mathrm{R}$ & S & $\mathrm{S}$ & $\mathrm{S}$ & $\mathrm{S}$ & $\mathbf{V}$ \\
\hline AR30 & Kermanshah & $8(\mathrm{~S})$ & S & $\mathrm{R}$ & S & S & S & S & S & VI \\
\hline AR31 & Kermanshah & $9(\mathrm{~S})$ & S & $\mathrm{R}$ & S & S & S & S & S & VI \\
\hline AR32 & Kermanshah & $9(\mathrm{~S})$ & S & $\mathrm{R}$ & S & $\mathrm{S}$ & S & S & S & VI \\
\hline
\end{tabular}

(Bivanij cv.). Increasing the disease severity for all isolates was same, although symptoms for isolates belonged to race VI appeared 2-3 days earlier. The blight severity was recorded on a 1-9 scale as suggested by Chongo et al. (2004) and Pande et al. (2011). In order to score differentials and to identify the pathogentic groups of isolates, plants with 0 to 4 score were categorized as resistant and 5-9 susceptible making simple the count of resistant and susceptible plant. Based on diseases severity rate of differentials cultivars, isolated grouped into six pathogenic groups as described by Shahriari et al. (2016).

The differential genotypes, ILC1929 was highly susceptible to all isolates, while ILC202 was the most resistant genotype that showed resistance responses to all isolates except against three isolates belonging to race VI. Differential genotypes, ILC5928 showed resistance reaction to most of isolates, except for 8 isolates belonging to pathotype III (Table 2). The most and least frequent races were race I and race $\mathrm{V}$, respectively. Isolated collected from "Kermanshah" province characterized for six races, while isolated from "Illam" province characterized only for race I, II and IV. Overall, results from differential genotypes grouped $A$. rabiei isolates into six pathotypes including 9 isolates for race I, 5 isolates for race II, 8 isolates for race III, 5 isolates for race IV, 2 isolates for race $\mathrm{V}$ and 3 isolates for race VI (Table 2). Principal component analysis (PCA) and cluster 


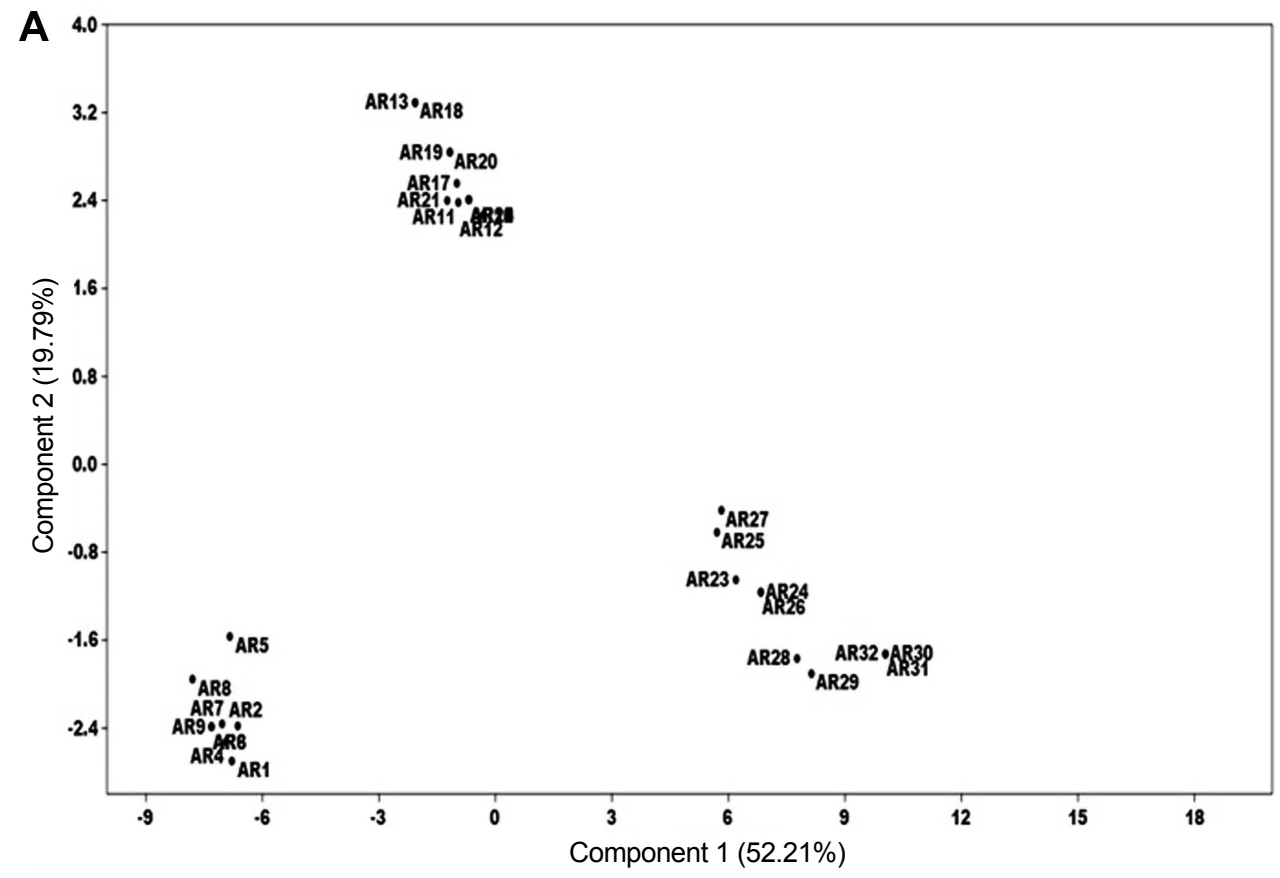

B

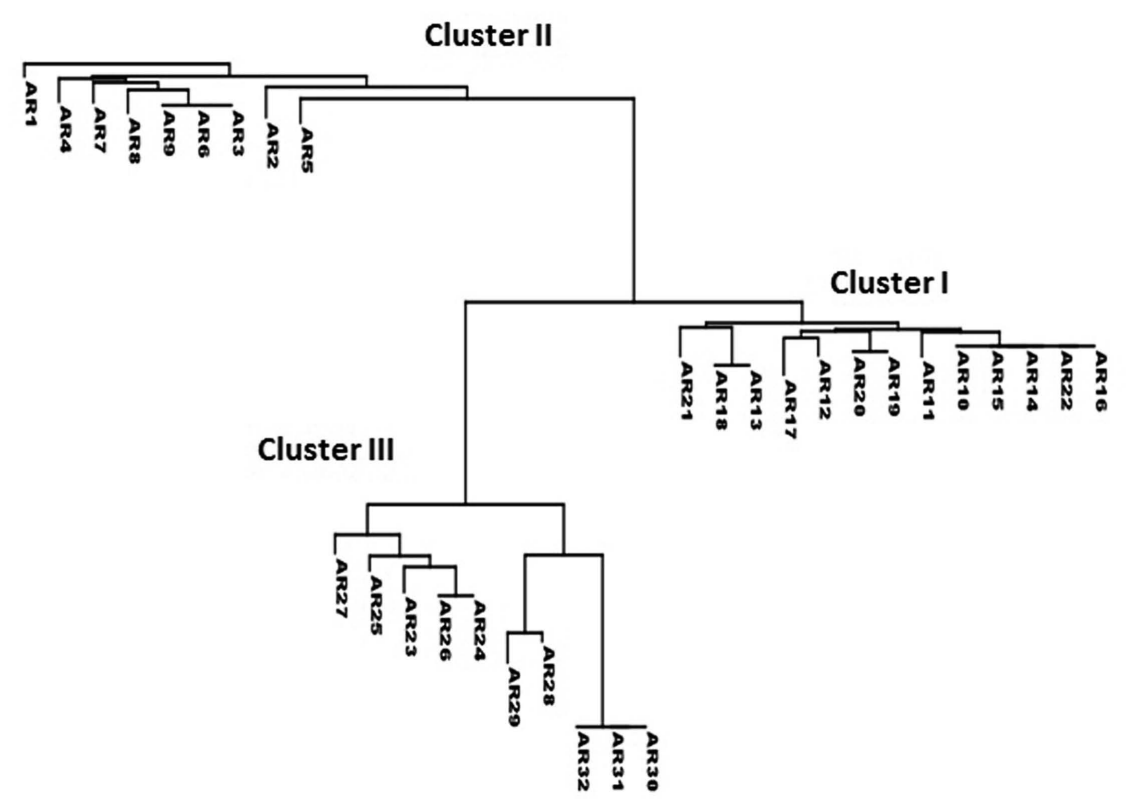

Fig. 1. Principal component analysis (A) and UNJ-based cluster analysis (B) of 32 A. rabiei isolates tested on seven chickpea differentials for disease severity rating $0-9$.

analysis of $A$. rabiei tested on differentials grouped isolates into three clusters (Fig. 1). Isolated belonged to race II and III grouped in first cluster, race I in second cluster and race $\mathrm{IV}, \mathrm{V}$ and VI in third cluster.

Resistance spectra of chickpea genotypes towards six races of $A$. rabiei. ANOVA analysis showed high significant $(P \leq 0.01)$ differences between chickpea genotypes
Table 3. Analysis of variance of the interaction between 165 chickpea genotypes and six Ascochyta rabiei isolates under greenhouse conditions

\begin{tabular}{lccc}
\hline S.O.V & $d f$ & Mean of Square & $F$ value \\
\hline Isolate & 5 & 32.19 & $7.75^{* *}$ \\
genotypes & 164 & 139.78 & $33.68^{* *}$ \\
Isolate $\times$ genotypes & 820 & 53.72 & $12.94^{* *}$ \\
Error & 1980 & 4.15 & \\
\hline
\end{tabular}




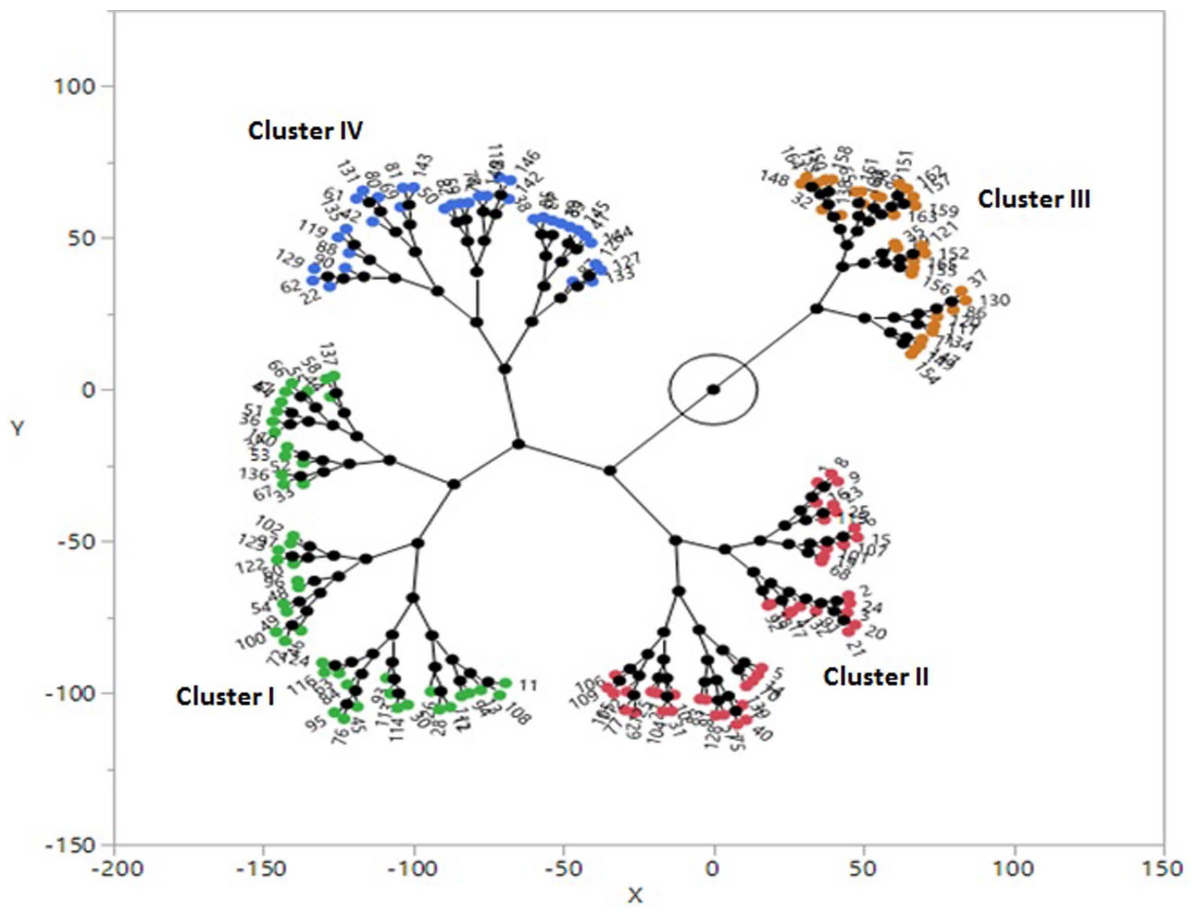

Fig. 2. Cluster analysis of chickpea genotypes based on mean disease severity data against six Ascochyta rabiei races. Note that 165 chickpea genotypes grouped in four distinct clusters. for their interactions with A. rabiei races (Table 3). The chickpea-isolates interaction effect analysis was highly significant $(P \leq 0.01)$. Significant $(P<0.01)$ differences among the chickpea genotypes indicated that they varied in their responses to infection by the different $A$. rabiei races.

The resistance spectra of 165 chickpea genotypes against six A. rabiei races presented in Supplementary Table 2. In order to characterize the susceptible and resistance genotypes based on score $0-9$, plants with 0 to 4 score were categorized as resistant and 5-9 susceptible, as described previously by Labdi et al. (2013) and Shahriari et al. (2016). Among all interactions $(\mathrm{n}=990), 259$ resistance responses (DS $\leq 4)$ were identified, which 129 responses were considered as highly resistances (DS $\leq 2$ ) (Supplementary Table 2). Resistance spectra of chickpea genotypes showed more resistance rate to race I $(49.70 \%)$ and race III $(35.15 \%)$, while there were no resistance genotypes to race VI. Out of 165 chickpea genotypes, 38 genotypes (23\%) showed no race specific responses and were susceptible to all races. In contrast, two genotypes (FLIP02-04C and FLIP06-65C) were resistant (disease severity $\leq 4$ ) to all races, except for race VI, while FIIP02-04C was also partially resistant to race VI. Nine genotypes showed specific resistance to four races (Supplementary Table 2). Cluster analysis and principal component analysis (PCA) based on mean disease severity data of each genotype against six $A$. rabiei races grouped 165 chickpea genotypes in four distinct clusters (Fig. 2 and 3). First cluster contained 46 genotypes including three Iranian cultivars (Arman, Hashem and Kaka).

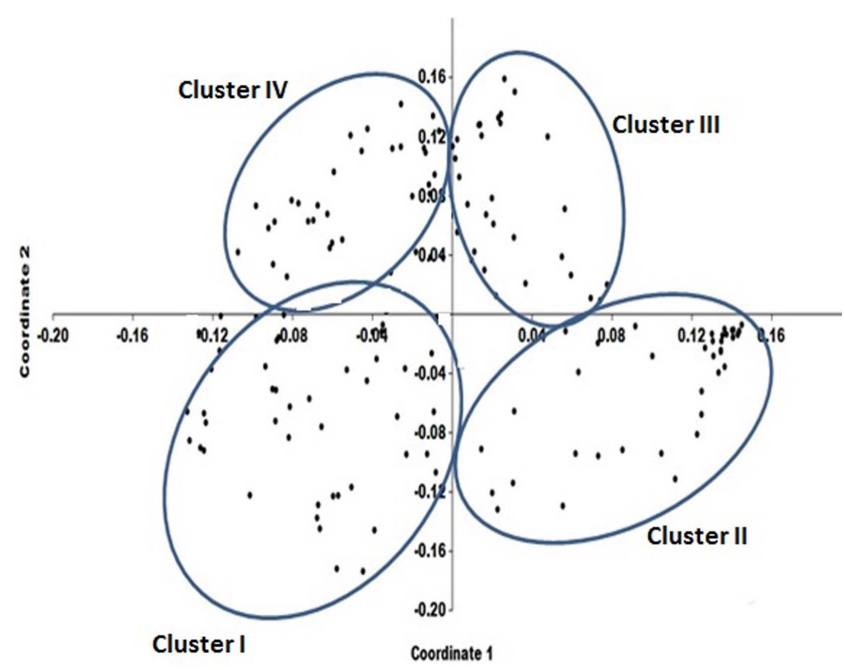

Fig. 3. Principal component analysis (PCA) of 165 chickpea genotypes based on mean disease severity data against six Ascochyta rabiei races.

Mean diseases severity for genotypes belonging to this cluster showed resistance spectra to race I and highly susceptible to other races (Table 4). Cluster II comprised 47 genotypes that mean diseases severity of genotypes showed resistance interaction to race III, moderate resistance to race I and IV and highly susceptible to race II, V and VI. Cluster III comprised 35 genotypes including three Iranian cultivars (ILC482, Adel and Azad). Genotypes belonged to this cluster showed resistance interaction to race I, race II and race III, moderately susceptibility to race IV and V 
Table 4. Means of chickpea genotypes response to different Ascochyta rabiei races in four clusters

\begin{tabular}{cccccccc}
\hline Cluster & No. Genotype & Race I (AR9) & Race II (AR13) & Race III (AR18) Race IV (AR23) Race V (AR28) Race VI (AR32) \\
\hline I & 46 & 3.14 & 8.00 & 6.30 & 6.35 & 8.04 & 8.08 \\
II & 47 & 4.20 & 6.43 & 3.17 & 4.02 & 5.98 & 7.38 \\
III & 35 & 2.94 & 2.24 & 4.43 & 5.54 & 5.45 & 7.59 \\
IV & 34 & 8.72 & 8.36 & 8.55 & 8.45 & 6.86 & 8.09 \\
\hline
\end{tabular}

and high susceptibility to race VI. Mean diseases severity of genotypes belonged to this cluster ranged from 2.24 (race II) to 7.59 (race VI). Cluster IV comprised 34 genotypes that all genotypes showed highly susceptibility to all $\mathrm{A}$. $\mathrm{ra}$ biei races (Table 4). All 'desi' chickpea accessions grouped in cluster IV and showed highly susceptibility to all $A$. $r a-$ biei races.

\section{Discussion}

Ascochyta blight (AB), caused by A. rabiei is one of the most destructive foliar diseases of chickpea worldwide. Complete yield losses in chickpea due to $\mathrm{AB}$ have been reported to occur under favorable environmental conditions (Pande et al., 2005; Sharma and Ghosh, 2016). Despite extensive breeding programs, narrow genetic base in chickpea to biotic and abiotic stresses has been reported (Ghaffari et al., 2014; Nguyen et al., 2005). Most of known AB-resistance sources used in breeding programs have non complete resistance (Chen and Muehlbaur, 2003). Characterization and development of new resistance sources to $\mathrm{AB}$ has been challenging and affected by several factors such as complex genetic basis of resistance and high pressure on the pathogen populations due to widespread cultivation of unique improved chickpea cultivars that confer to high variability in pathogen population (Collard et al., 2003; Mehrabi et al., 2015). Therefore, characterization of new resistance sources to $\mathrm{AB}$ and utilization in breeding programs is prerequisite. In the present study, initially 32 A. rabiei isolates collected from west of Iran were analyzed for their pathogenicity on seven different chickpea differential genotypes. The A. rabiei isolates were characterized for six different pathotypes/races, where the race I and race III have more frequent in isolates. Race V and VI showed highly virulence on most of differential, while race I showed least aggressiveness.

The present results are supported by the findings of Turkkan and Dolar (2006) and Shahriari et al. (2016) who reported 6 distinct pathotypes/races of $A$. rabiei based virulence reactions on chickpea differential genotypes. Variable number of races of $A$. rabiei has been reported previously (Ali et al., 2013; Kumar et al., 2005; Peever et al., 2012).
This variability in reported pathotypes/races for chickpea might be due to unavailability of standardized differentials and existence of high genetic variation of A. rabiei population worldwide (Baite and Dubey, 2018).

Our finding is in agreement with earlier reports for a difference in aggressiveness of $A$. rabiei isolates from Iran (Shokouhifar et al., 2003; Vafaei et al., 2015) and India (Kumar et al., 2005). Highly genetic diversity and aggressiveness of $A$. rabiei isolates collected from "Kermanshah" province can be concluded by highly sexual reproduction and recombination in A. rabiei population or selection pressure imposed by improved cultivars on pathogen that lead to change of A. rabiei local population and breaking down of resistance. These finding is important as complementary information about pathogenic variability and race dispersive of Iranian A. rabiei isolates.

In the second experiment we report the interactions of 165 chickpea genotypes against six A. rabiei races. Among all interactions (990), we identified 259 resistance interactions (disease severity $P \leq 4$ ), which 129 was highly resistance. Approximately, half of genotypes were resistance to race I, while all tested chickpea genotypes were susceptible to race VI. Our results showed that all black chickpea genotypes (Desi type) were highly susceptible to all $A$. rabiei races. This is in agreement with previous reports on chickpea Desi genotypes (Ahmad et al., 2014; Reddy et al., 1992), even there are a few reports for resistance sources in Desi chickpea genotypes (Kimurto et al., 2013). This could be concluded by using different isolates, intervals of inoculation and different methods of grouping genotypes into resistant or susceptible (Labdi et al., 2013). In this study, nine genotypes showed resistant interaction with race I to race $\mathrm{V}$ and two genotypes (FLIP02-04C and FLIP06-65C) were resistant to all races (moderately susceptible/resistant to race VI). These genotypes may possess broad-spectrum resistance gene(s) or a combination of diverse yet-unknown AB-resistant genes and, hence, can be effectively used in chickpea breeding programs. All Iranian chickpea cultivars showed susceptible interaction with $A$. rabiei race, except for race I. Therefore, this narrow resistance background of improved cultivars, forced breeders to introduce new resistant sources of $\mathrm{AB}$ into Iranian chickpea breeding pro- 
grams for effective management of this disease in dryland areas.

Interactions between isolates or races used in this study, showed the lack of a genotype with complete resistance. Genetics of resistance to $\mathrm{AB}$ in chickpea is quantitative and controlled by a single dominant or recessive gene (Labdi et al., 2013; Singh and Reddy, 1989, 1991) that can be easily broken by appearance of new races of pathogen (Ahmad et al., 2014; Ilyas et al., 2007). Most of resistance sources to $\mathrm{AB}$ in chickpea have been supplied by ICARDA and ICRISAT and used in international breeding programs worldwide. A number of resistance sources identifies, although non genotypes possesses complete resistance (Pande et al., 2011; Sharma and Ghosh, 2016). Most of the genotypes used in this study originated from ICARDA and are common resistance sources in many different chickpea breeding programs worldwide as well as in Iran (Kanouni et al., 2011; Shahriari et al., 2016). They have same genotypes (FLIP98-52C, FLIP98-28C, FLIP98-15C and FLIP9828C) in their pedigree; Therefore, this narrow genetic base of resistance sources is a challenge for finding a genotype with complete resistance to all known $A$. rabiei races.

In conclusion, the results of this study provide useful information not only about virulence profile of $A$. rabiei isolates collected from west of Iran but also elucidate the resistance pattern of chickpea genotypes against different races of $A$. rabiei. We found that different races of $A$. rabiei have a broad virulence spectrum against large studied chickpea germplasm used in this study. Nevertheless, it appears that employment of resistance sources with different interactions with $A$. rabiei races could be very useful to control the disease. These findings could be considerably important for selection and integration of AB-resistance genes into chickpea breeding programs for $\mathrm{AB}$ management. The newly identified highly resistance genotypes may contain novel resistance genes that their identifications remain to be investigated in the future.

\section{References}

Aghamiri, A., Mehrabi, R. and Talebi, R. 2015. Genetic diversity of Pyrenophera tritici-repentis isolates, the causal agent of wheat tan spot disease from Northern Iran. Iran. J. Biotechnol. 13:39-44.

Ahmad, S., Khan, M. A., Sahi, S. T. and Ahmad, R. 2014. Identification of resistant sources in chickpea against chickpea blight disease. Arch. Phytopathol. Plant Prot. 47:1885-1892.

Ali, H., Alam, S. S., Attanayake, R. N., Rahman, M. and Chen, W. 2012. Population structure and mating type distribution of the chickpea blight pathogen Ascochyta rabiei from Pakistan and the United States. J. Plant Pathol. 94:99-108.

Ali, H., Alam, S. S. and Iqbal, N. 2013. Genetic and pathogenic variability of Ascochyta rabiei isolates from Pakistan and Syria as detected by universal rice primers. J. Plant. Pathol. Microbiol. 4:1000212.

Atik, O., Baum, M., El-Ahmed, A., Ahmed, S., Abang, M. M., Yabrak, M. M., Murad, S., Kabbabeh, S. and Hamwieh, A. 2011. Chickpea ascochyta blight: Disease status and pathogen mating type distribution in Syria. J. Phytopathol. 159:443449.

Baite, M. S. and Dubey, S. C. 2018. Pathogenic variability of Ascochyta rabiei causing blight of chickpea in India. Physiol. Mol. Plant Pathol. 102:122-127.

Ben Mohamed, L., Cherif, M., Harrabi, M., Galbraith, R. F. and Strange, R. N. 2010. Effects of sowing date onseverity of blight caused by Ascochyta rabiei and yield components of five chickpea cultivars grown under two climatic conditions in Tunisia. Eur. J. Plant Pathol. 126:293-303.

Bhardwaj, R., Sandhu, J. S., Kaur, L., Gupta, S. K., Gaur, P. M. and Varshney, R. 2010. Genetics of ascochyta blight resistance in chickpea. Euphytica 171:337-343.

Chen, W. and Muehlbauer, F. 2003. An improved technique for virulence assay of Ascochyta rabiei on chickpea. Int. Chickpea Pigeonpea Newslett. 10:31-33.

Chen, W., Coyne, C. J., Peever, T. L. and Muehlbauer, F. J. 2004. Characterization of chickpea differentials for pathogenicity assay of ascochyta blight and identification of chickpea accessions resistant to Didymella rabiei. Plant Pathol. 53:759769.

Chongo, G., Gossen, B. D., Buchwaldt, L., Adhikari, T. and Rimmer, S. R. 2004. Genetic diversity of Ascochyta rabiei in Canada. Plant Dis. 88:4-10.

Collard, B. C. Y., Pang, E. C. K., Ades, P. K. and Taylor, P. W. J. 2003. Preliminary investigation of QTLs associated with seedling resistance to ascochyta blight from Cicer echinospermum, a wild relative of chickpea. Theor. Appl. Genet. 107:719-729.

Dey, S. K. and Singh, G. 1993. Resistance to ascochyta blight in chickpea - Genetic basis. Euphytica 68:147-153.

Gan, Y. T., Siddique, K. H. M., MacLeod, W. J. and Jayakumar, P. 2006. Management options for minimizing the damage by ascochyta blight (Ascochyta rabiei) in chickpea (Cicer arietinum L.). Field Crops Res. 97:121-134.

Ghaffari, P., Talebi, R. and Keshavarzi, F. 2014. Genetic diversity and geographical differentiation of Iranian landrace, cultivars, and exotic chickpea lines as revealed by morphological and microsatellite markers. Physiol. Mol. Biol. Plants 20:225-233.

Hajibarat, Z., Saidi, A., Hajibarat, Z. and Talebi, R. 2015. Characterization of genetic diversity in chickpea using SSR markers, start codon targeted polymorphism (SCoT) and conserved DNA-derived polymorphism (CDDP). Physiol. Mol Biol. Plants 21:365-373.

Ilyas, M. B., Chaudhry, M. A., Javed, N., Ghazanfar, M. U. and Khan, M. A. 2007. Sources of resistance in chickpea germ- 
plasm against Ascochyta blight. Pak. J. Bot. 39:1843-1847. Jamalabadi, J. G., Saidi, A., Karami, E., Kharkesh, M. and Talebi, R. 2013. Molecular mapping and characterization of genes governing time to flowering, seed weight, and plant height in an intraspecific genetic linkage map of chickpea (Cicer arietinum). Biochem. Genet. 51:387-397.

Jan, H. and Wiese, M. V. 1991. Virulence forms of Ascochyta rabiei affecting chickpea in the Palouse. Plant Dis. 75:904-906.

Kanouni, H., Taleei, A. and Okhovat, M. 2011. Ascochyta blight (Ascochyta rabiei (Pass.) Lab.) of chickpea (Cicer arietinum L.): Breeding strategies for resistance. Int. J. Plant Breed. Genet. 5:1-22.

Kimurto, P. K., Towett, B. K., Mulwa, R. S., Njogu, N., Jeptanui, L. J., Rao, G. N., Silim, S., Kaloki, P., Korir, P. and Macharia, J. K. 2013. Evaluation of chickpea genotypes for resistance to Ascochyta blight (Ascochyta rabiei) disease in the dry highlands of Kenya. Phytopathol. Mediterr. 52:212-221.

Kumar, A., Mitter, N. and Agarwal, R. 2005. Characterization of pathotype diversity in nine isolates of Ascochyta rabiei based on virulence and DNA polymorphism. Ann. Plant Prot. Sci. 13:404-409.

Labdi, M., Malhotra, R. S., Benzohra, I. E. and Imtiaz, M. 2013. Inheritance of resistance to Ascochyta rabiei in 15 chickpea germplasm accessions. Plant Breed. 132:197-199.

Malik, S. R., Iqbal, S. M., Iqbal, U., Ahmad, I. and Haqqani, A. M. 2005. Response of chickpea lines to Ascochyta rabiei at two growing stage. Caspian J. Environ. Sci. 3:173-177.

Mehrabi, R., Makhdoomi, A. and Jafar-Aghaie, M. 2015. Identification of new sources of resistance to septoria tritici blotch caused by Zymoseptoria tritici. J. Phytopathol. 163:84-90.

Nene, Y. L., Haware, M. P. and Reddy, M. V. 1981. Chickpea diseases: Resistance-screening techniques. International Crops Research Institute for the Semi-Arid Tropics, Patancheru, India. $11 \mathrm{pp}$.

Nguyen, T. T., Taylor, P. W. J., Redden, R. J. and Ford, R. 2005. Resistance to Ascochyta rabiei (Pass.) Lab. in a wild Cicer germplasm collection. Aust. J. Exp. Agric. 45:1291-1296.

Pande, S., Siddique, K. H. M., Kishore, G. K., Baaya, B., Gaur, P. M., Gowda, C. L. L., Bretag, T. W. and Crouch, J. H. 2005. Ascochyta blight of chickpea (Cicer arietinum L.): A review of biology, pathogen city, and disease management. Aust. J. Agric. Res. 56:317-332.

Pande, S., Sharma, M., Gaur, P. M., Tripathi, S., Kaur, L., Basandrai, A., Khan, T., Gowda, C. L. L. and Siddique, K. H. M. 2011. Development of screening techniques and identification of new sources of resistance to Ascochyta blight disease of chickpea. Aust. Plant Pathol. 40:149-156.

Peever, T. L., Chen, W., Abdo, Z. and Kaiser, W. J. 2012. Genetics of virulence in Ascochyta rabiei. Plant Pathol. 61:754760 .
Reddy, M. V. and Kabbabeh, S. 1985. Pathogenic variability in Ascochyta rabiei (Pass.) Lab. in Syria and Lebanon. Phytopathol. Mediterr. 24:265-266.

Reddy, M. V., Singh, K. B. and Malhotra, R. S. 1992. Multilocation evaluation of chickpea germplasm and breeding lines for resistance to Ascochyta blight. Phytopathol. Mediterr. 31:5966.

Rhaiem, A., Chérif, M., Peever, T. L. and Dyer, P. S. 2008. Population structure and mating system of Ascochyta rabiei in Tunisia: evidence for the recent introduction of mating type 2 . Plant Pathol. 57:540-551.

Shahriari, D., Torabi, M. and Kangarloo, S. 2016. Response of some chickpea genotypes to races of Ascochyta rabiei cause of ascochyta blight in greenhouse. Seed Plant Improv. J. 32:479-492.

Sharma, M. and Ghosh, R. 2016. An update on genetic resistance of chickpea to ascochyta blight. Agronomy 6:18.

Shokouhifar, F., Bagheri, A., Falahati, R. M. and Malekzadeh, S. 2003. Pathotyping of Ascochyta rabiei isolates in Iran. J. Agric. Sci. Nat. Resour. 10:217-232.

Singh, K. B. and Reddy, M. V. 1983. Inheritance of resistance to Ascochyta blight in chickpea. Crop Sci. 23:9-10.

Singh, K. B. and Reddy, M. V. 1989. Genetics of resistance to Ascochyta blight in four chickpea lines. Crop Sci. 29:657-659.

Singh, K. B. and Reddy, M. V. 1990. Patterns and susceptibility to races of Ascochyta rabiei among germplasm accessions and breeding lines of chickpea. Plant Dis. 74:127-129.

Singh, K. B. and Reddy, M. V. 1991. Advances in disease-resistance breeding in chickpea. Adv. Agron. 45:191-222.

Talebi, R., Naji, A. M. and Fayaz, F. 2008. Geographical patterns of genetic diversity in cultivated chickpea (Cicer arietinum L.) characterized by amplified fragment length polymorphism. Plant Soil Environ. 54:447-452.

Turkkan, M. and Dolar, F. S. 2009. Determination of pathogenic variability of Didymella rabiei, the agent of ascochyta blight of chickpea in Turkey. Turk. J. Agric. For. 33:585-591.

Vafaei, S. H., Rezaee, S., Moghadam, A. A. and Zamanizadeh, H. R. 2015. Virulence diversity of Ascochyta rabiei the causal agent of Ascochyta blight of chickpea in the western provinces of Iran. Arch. Phytopathol. Plant Prot. 48:921-930.

Vail, S. and Banniza, S. 2008. Structure and pathogenic variability in Ascochyta rabiei populations on chickpea in the Canadian prairies. Plant Pathol. 57:665-673.

van der Maesen, L. J. G. 1987. Origin, history, and taxonomy of chickpea. In: The chickpea, eds. by M. C. Saxena and K. B. Singh, pp. 11-34. CABI, Wallinford, UK.

Younessi, H., Okhovat, S. M., Hejaroud, G. A., Zad, S. J., Taleei, A. R. and Zamani, M. R. 2004. Virulence variability of $A s-$ cochyta rabiei isolates on chickpea cultivars in Kermanshah province. Iran J. Plant. Pathol. 39:213-228. 